\title{
PEMANFAATAN ZEOLIT ALAM, H-ZEOLIT ALAM DAN Ti-H-ZEOLIT ALAM MALANG SEBAGAI KATALIS REAKSI ISOMERISASI GLUKOSA
}

\author{
Aisyah Erlynata, Suci Amalia, Tri Kustono Adi, Susi Nurul Khalifah \\ Jurusan Kimia, Fakultas Sains dan Teknologi, UIN Maulana Malik Ibrahim Malang
}

\begin{abstract}
The utilization of natural zeolite, natural H-zeolite and natural Ti-H-zeolite from Malang as catalysts reaction of glucose isomerization were applied for determining influence of acidity and catalysts activity of natural zeolite, natural H-zeolite and natural Ti-H-zeolite Malang on isomerization reaction of glucose. Natural zeolite was activated using $\mathrm{NH}_{4} \mathrm{NO}_{3}$ acid $2 \mathrm{M}$ solution until generated $\mathrm{H}$-zeolite. Ti metal has impregnationded on H-zeolite by concentration of $\mathrm{TiO}_{2} 0,2 \mathrm{M}$. It was applied hydrometal process method using temperature of 90 ${ }^{\circ} \mathrm{C}$ for 12 hours and calcined on temperature of $500{ }^{\circ} \mathrm{C}$ for 4 hours. Glucose isomerization was applied using the batch method with various of reaction time of 30, 60, 90 and 120 minutes and analyzed using polarimeter. The catalysts characterization involved of acidity test using ammonia adsorption method and pyridine adsorption. Pyridine adsorption was analyzed using FTIR and XRD.

The results showed that the acidity of ammonia adsorption on natural zeolite, $\mathrm{H}$-zeolite and Ti-H-zeolite Malang respective were 0,$188 ; 0,281$ and $0,387 \mathrm{mmol} / \mathrm{g}$, respective the acidity of pyridine adsorption showed that natural Ti-H-zeolite Malang has Brønsted acid side of $0,153 \mathrm{mmol} / \mathrm{g}$. The XRD showed that modification process of zeolite did not change structure and Ti on the catalyst surface. The activity of Ti-H-Zeolite catalyst on glucose isomerization reaction was achieved on 120 hours with glucose conversion of $22,09 \%$.
\end{abstract}

Key Words: Natural Zeolite, Titanium Metal, Glucose Isomerization, Polarimeter

\section{ABSTRAK}

Pemanfaatan zeolit alam, H-zeolit alam dan Ti-H-zeolit alam Malang sebagai katalis reaksi isomerisasi glukosa telah berhasil dilakukan untuk mengetahui pengaruh keasaman dan efektivitas katalis zeolit alam, Hzeolit alam dan Ti-H-zeolit alam Malang pada reaksi isomerisasi glukosa. Zeolit alam diaktivasi dengan menggunakan larutan asam $\mathrm{NH}_{4} \mathrm{NO}_{3} 2 \mathrm{M}$ sehingga dihasilkan $\mathrm{H}$-zeolit. Logam Ti diimpregnasikan pada H-zeolit dengan konsentrasi $\mathrm{TiO}_{2} 0,2 \mathrm{M}$. Metode yang digunakan adalah proses hidrotermal menggunakan suhu $90{ }^{\circ} \mathrm{C}$ selama 12 jam dilanjutkan dengan kalsinasi pada suhu $500{ }^{\circ} \mathrm{C}$ selama 4 jam. Isomerisasi glukosa dilakukan menggunakan metode batch dengan variasi waktu reaksi 30, 60, 90 dan 120 menit dan dianalisis menggunakan polarimeter. Karakterisasi katalis meliputi keasaman menggunakan metode adsorpsi amoniak dan metode adsorpsi piridin yang dianalisis menggunakan FTIR serta kristalinitas katalis menggunakan XRD.

Hasil penelitian menunjukkan bahwa keasaman adsorpsi amoniak katalis zeolit alam, H-zeolit dan Ti$\mathrm{H}$-zeolit alam Malang berturut-turut adalah sebesar 0,188;0,281 dan 0,387 mmol/g. Untuk keasaman adsorpsi piridin katalis Ti-H-zeolit alam Malang memiliki sisi asam Brønsted sebesar 0,153 mmol/g. Hasil karakterisasi XRD diketahui bahwa proses modifikasi pada zeolit tidak menyebabkan perubahan struktur dan Ti telah berada pada permukaan katalis. Aktivitas katalis Ti-H-Zeolit terhadap reaksi isomerisasi glukosa pada $110{ }^{\circ} \mathrm{C}$ selama 120 menit dengan konversi glukosa sebesar 22,09\%.

Kata kunci : Zeolit Alam, Logam Titanium, Isomerisasi Glukosa, Polarimeter

\section{PENDAhULUAN}

Penggunaan biokatalitik untuk isomerisasi glukosa menjadi fruktosa merupakan proses terbesar yang banyak digunakan di dunia. Reaksi isomerisasi ini biasanya dilakukan dengan bantuan enzim. Gaily, dkk., (2010) telah melaporkan hasil konversi glukosa $40 \%$ menggunakan katalis enzim yang diimobilisasi 31
(Sweetzyme IT). Konversi glukosa menjadi fruktosa $42 \%$ juga telah dihasilkan menggunakan enzim isomerase (Zhang, dkk., 2004). Namun, dalam penelitian ini akan dilakukan isomerisasi glukosa menjadi fruktosa menggunakan bahan katalis anorganik. Kenyataannya, bahan katalis anorganik tidak seperti reaksi enzimatik, memiliki dan mempertahankan aktivitas 
tinggi pada siklus berlipat-ganda, mudah diregenerasi dan bekerja pada rentang temperatur yang luas serta efektif beroperasi pada kondisi asam (Situmeang dan Fransisca, 2011).

Moliner, dkk. (2010) melaporkan logam Ti yang diembankan pada zeolit sintetik dapat digunakan sebagai katalis dalam reaksi isomerasi glukosa menjadi fruktosa yaitu Ti-Beta dan Ti-MCM-41 menghasilkan konversi glukosa secara berturut-turut 50 dan $23 \%$ serta selektivitas fruktosa 45 dan $28 \%$. Berdasarkan penelitian Moliner, dkk. (2010) di atas isomerisasi glukosa menjadi fruktosa menggunakan zeolit sintetik dapat digantikan menggunakan zeolit alam.

Hagedus (1987) melaporkan bahwa logam-logam yang diembankan ke dalam zeolit akan menyebabkan luas permukaan relatif besar, yang pada akhirnya akan memperbesar luas kontak antara katalis dan reaktan, sehingga reaksi berjalan cepat. Logam ini secara langsung dapat digunakan sebagai katalis tanpa diembankan terlebih dahulu pada pengemban, tetapi memiliki kelemahan, diantaranya luas permukaan yang relatif kecil dan selama proses katalitik dapat terjadi penggumpalan (Augustine, 1996). Sehingga untuk mencegah terjadinya penggumpalan perlu ditambahkan pengemban.

Pada penelitian ini akan dilakukan pengembanan logam $\mathrm{Ti}$ pada zeolit alam Malang yang selanjutnya akan digunakan sebagai katalis isomerisasi glukosa. Karakterisasi dilakukan setelah mendapatkan hasil sintesis adalah keasaman permukaan metode adsorpsi amoniak dan adsorpsi piridin, XRD (X-Ray Diffraction) dan hasil isomerisasi glukosa didapatkan melalui polarimeter. Tujuan penelitian ini untuk mengetahui keasaman katalis dan aktivitas katalitik dari zeolit alam, H-zeolit alam dan Ti-H-zeolit alam Malang pada reaksi isomerisasi glukosa.

\section{METODE PENELITIAN}

Bahan yang digunakan dalam penelitian ini adalah zeolit alam Malang,
$\mathrm{NH}_{4} \mathrm{NO}_{3} 2 \mathrm{M}$, amoniak, kertas saring, glukosa monohidrat, fruktosa, $\mathrm{TiO}_{2}$ dan aquades.

\section{Preparasi Zeolit Alam}

Zeolit alam Malang halus sebanyak 250 gram direndam dalam $500 \mathrm{~mL}$ air bebas ion (akuades) sambil diaduk dengan pengaduk magnet selama sehari semalam (24 jam) pada suhu kamar $\left( \pm 25{ }^{\circ} \mathrm{C}\right)$, disaring dan endapan yang diperoleh dikeringkan dalam oven pada suhu $100{ }^{\circ} \mathrm{C}$ selama 24 jam. Selanjutnya, endapan ditumbuk dan diayak dengan menggunakan ayakan ukuran 100 mesh dan 250 mesh.

\section{Aktivasi Zeolit Alam}

Padatan zeolit kering yang lolos dari ayakan 100 mesh dan tertahan pada ayakan 250 mesh ditimbang 50 gram dan ditambahkan dengan larutan $\mathrm{NH}_{4} \mathrm{NO}_{3} 2 \mathrm{M}$ sebanyak $100 \mathrm{~mL}$. Kemudian campuran diaduk secara kontinyu selama 2 jam sampai dengan 4 jam tanpa pemanasan. Campuran disaring dan dicuci dengan aquades sampai $\mathrm{pH}$ filtrat netral. Padatan yang diperoleh dipanaskan pada suhu 110 ${ }^{\circ} \mathrm{C}$ dalam oven selam $12 \mathrm{jam}$, sehingga menghasilkan $\mathrm{H}$-zeolit.

\section{Modifikasi Ti-H-Zeolit Alam Malang dengan Metode Impregnasi}

Ditimbang 10 gram H-zeolit yang telah diaktivasi. Kemudian dicampur dengan larutan $\quad \mathrm{TiO}_{2} \quad 20 \mathrm{~mL}$ dengan konsentrasi 0,2 M. Campuran diaduk selama 2 jam, kemudian dilakukan proses hidrotermal dengan cara dipanaskan pada suhu $90{ }^{\circ} \mathrm{C}$ dalam oven selama 12 jam. Selanjutnya zeolit hasil hidrotermal didiamkan selama 24 jam. Kemudian dilakukan penyaringan. Endapan hasil penyaringan kemudian dioven dengan suhu $100{ }^{\circ} \mathrm{C}$ selama 2 jam untuk menghilangkan air. Selanjutnya semua sampel zeolit terimpregnasi diaktivasi dengan cara kalsinasi pada suhu $500{ }^{\circ} \mathrm{C}$ selama 4 jam dalam tanur. Pada tahap ini akan dihasilkan katalis Ti-H-zeolit.

\section{Karakterisasi}

Katalis Ti-H-zeolit alam dikarakterisasi menggunakan difraksi sinar$\mathrm{X}$ (XRD) untuk mengetahui fase kristal 
sampel zeolit sebelum dan setelah dilakukan modifikasi. Analisis keasaman adsorpsi amoniak dilakukan terhadap katalis zeolit alam, H-zeolit alam dan Ti-Hzeolit alam Malang dengan metode gravimetri, yaitu dengan mengukur selisih antara berat sampel katalis zeolit yang mengadsorpsi amoniak dan berat sampel zeolit tanpa amoniak. Zeolit dengan keasaman adsorpsi amoniak yang terbesar dianalisis keasaman permukaannya menggunakan adsorpsi piridin. Sampel sebanyak $10 \mathrm{mg}$ diletakkan pada pemegang sampel, dan dimasukkan ke dalam sel kaca yang mempunyai jendela terbuat dari kalsium florida, $\mathrm{CaF}_{2}$. Selanjutnya, sel kaca dipanaskan pada suhu $400{ }^{\circ} \mathrm{C}$ selama 4 jam. Jenis situs asam Brønsted ditentukan menggunakan molekul piridin sebagai basa. Piridin diadsorb pada suhu ruang selama satu jam, dilanjutkan dengan desorpsi pada $150{ }^{\circ} \mathrm{C}$ selama tiga jam. Spektra inframerah direkam pada suhu kamar pada daerah $1700-1400 \mathrm{~cm}^{-} 1$. Jumlah sisi asam dihitung berdasarkan persamaan yang telah diperkenalkan oleh Emeis (1993).

\section{Uji Aktivitas Katalitik}

\section{A. Penentuan Sudut Putar Bidang Polarisasi Spesifik Glukosa}

Penentuan sudut putar bidang polarisasi spesifik glukosa $\left(\alpha_{\mathrm{sg}}\right)$ dilakukan dengan cara diukur sudut putar bidang polarisasi pada rentang konsentrasi glukosa yaitu 2, 4, 6, 8, 10 dan $12 \%$ dalam $25 \mathrm{~mL}$ aquades menggunakan polarimeter.

\section{B. Penentuan Sudut Putar Bidang Polarisasi Spesifik Fruktosa \\ Penentuan sudut putar bidang} polarisasi spesifik fruktosa $\left(\alpha_{\mathrm{sf}}\right)$ dilakukan dengan cara diukur sudut putar bidang polarisasi pada rentang konsentrasi glukosa yaitu $2,4,6,8,10$ dan $12 \%$ dalam $25 \mathrm{~mL}$ aquades menggunakan polarimeter.

\section{Isomerisasi Glukosa}

Isomerisasi glukosa dilakukan dengan metode batch menggunakan erlenmeyer $500 \mathrm{~mL}$ yang dilengkapi dengan pengaduk, termometer dan refluks 33 condenser. Sebanyak $50 \mathrm{~mL}$ aquades ditambahkan ke dalam 5 g glukosa dalam erlenmeyer. Kemudian larutan dipanaskan pada suhu $110^{\circ} \mathrm{C}$ dengan penangas minyak. Selanjutnya ditambahkan zeolit alam Malang sebanyak $1 \mathrm{~g}$ dengan kecepatan pengadukan $300 \mathrm{rpm}$ dan reaksi berlangsung selama 30, 60, 90 dan 120 menit. Dalam setiap waktu tersebut reaksi dihentikan. Kemudian disentrifuge dan ditentukan konsentrasi glukosa setiap waktu reaksi isomerisasi dengan cara dipipet $1 \mathrm{~mL}$ hasil isomerisasi glukosa kemudian dimasukkan dalam labu takar $25 \mathrm{~mL}$ dan ditambah akuades sampai tanda batas. Selanjutnya diukur sudut putar bidang polarisasinya menggunakan polarimeter secara triplo dan dihitung konsentrasi glukosa setiap waktu. Prosedur ini juga dilakukan terhadap zeolit alam Malang hasil aktivasi dan modifikasi.

Prosen konversi glukosa ditentukan dari selisih konsentrasi glukosa awal dengan konsentrasi gukosa akhir menggunakan persamaan:

$$
\% \text { konversi }=\frac{\text { Konsentrasi glukosa awal }- \text { konsentrasi glukosa akhir }}{\text { Konsentrasi glukosa awal }} \times 100 \%
$$

\section{HASIL DAN PEMBAHASAN 1. Karakterisasi Difraksi Sinar-X (XRD)} XRD dilakukan untuk mengidentifikasi kristalinitas zeolit alam dan zeolit alam yang telah dimodifikasi dengan penambahan logam Ti 0,2 M serta untuk mengetahui kemungkinan pembentukan fasa baru selama modifikasi. Data difraktogram zeolit alam Malang dan zeolit alam Malang modifikasi logam Ti 0,2 M ditunjukkan pada Gambar 1.

Pada Gambar 1 didapatkan hasil bahwa terjadi pergeseran sudut $2 \theta$ yang tidak terlalu jauh antara zeolit alam dengan zeolit alam modifikasi. Hal ini menunjukkan bahwa dengan penambahan logam $\mathrm{Ti}$ struktur zeolit tipe mordenit masih bisa dipertahankan karena tidak adanya puncak $2 \theta$ yang baru. Selain itu, didapatkan bahwa terjadi penurunan intensitas pada zeolit alam. Adanya 
penurunan intensitas puncak pada zeolit alam modifikasi logam $\mathrm{Ti} \quad 0,2 \quad \mathrm{M}$ menunjukkan bahwa Ti diperkirakan berada pada permukaan zeolit alam tidak masuk ke dalam struktur zeolit alam.
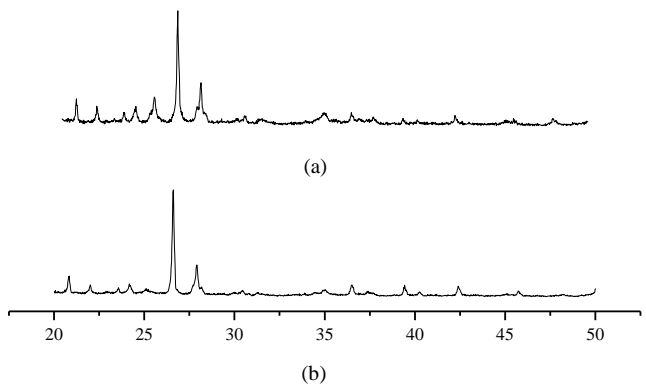

Gambar 1 Difraktogram hasil karakterisasi

(a) zeolit alam Malang modifikasi logam Ti 0,2 $\mathrm{M}$ dan

(b) zeolit alam Malang (Botianovi, 2012)

\section{Keasaman Adsorpsi Amoniak}

Sifat keasaman zeolit merupakan karakter penting dalam menentukan aktifitas katalis. Jumlah keasaman (kuantitatif) dalam zeolit diukur dengan metode gravimetri, yaitu dengan mengukur selisih antara berat sampel katalis zeolit yang mengadsorpsi amoniak dan berat sampel zeolit tanpa amoniak. Hasil keasaman sampel adsorpsi amoniak dapat dilihat pada Tabel 1.

Tabel 1 Keasaman adsorpsi amoniak

\begin{tabular}{lc}
\hline \multicolumn{1}{c}{ Sampel } & $\begin{array}{c}\text { Keasaman } \\
(\mathrm{mmol} / \mathrm{g})\end{array}$ \\
\hline Zeolit alam & 0,188 \\
H-zeolit alam & 0,281 \\
Ti-H-zeolit alam & 0,387 \\
\hline
\end{tabular}

\section{Keasaman Adsorpsi Piridin}

Jenis dan jumlah situs asam dalam sampel diamati dan ditentukan dengan menggunakan adsorpsi piridin. Pada interaksinya dengan sisi asam Brønsted, molekul piridin terprotonasi dan teradsorp di bilangan gelombang inframerah spesifik sekitar 1540-1545 $\mathrm{cm}^{-1}$, sedangkan interaksinya dengan sisi asam Lewis terjadi karena pembentukan kompleks ikatan koordinasi antara pasangan elektron bebas dari molekul piridina dengan orbital kosong dari permukaan padatan. Interaksi ini memunculkan pita serapan di daerah inframerah antara 1440-1452 $\mathrm{cm}^{-1}$ (Platon dan Thomson, 2003). Pita adsorpsi pada daerah piridin zeolit modifikasi (1700-1400 $\mathrm{cm}^{-1}$ ) ditunjukkan pada Gambar 2 .

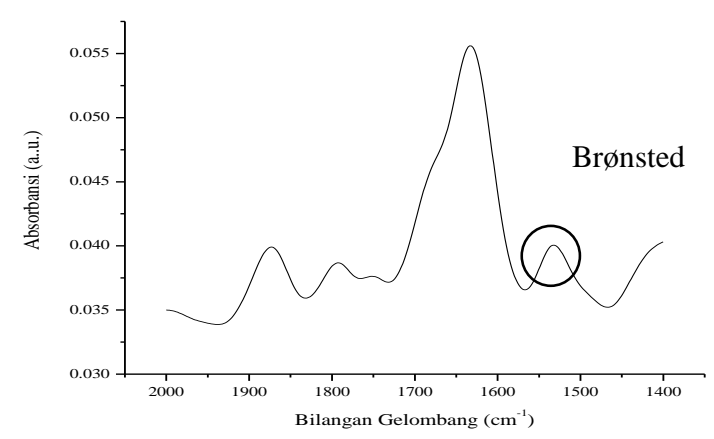

Gambar 2 Spektra FTIR daerah piridin zeolit modifikasi $\mathrm{TiO}_{2}$ 0,2 M

Pada Gambar 2 spektra inframerah untuk zeolit modifikasi menunjukkan vibrasi piridin disekitar $1542 \mathrm{~cm}^{-1}$. Puncak ini menunjukkan vibrasi regangan $\mathrm{C}-\mathrm{C}$ dari ion piridinium yang mengindikasikan adanya sisi asam Brønsted pada katalis. Sedangkan sisi asam Lewis tidak muncul pada sampel ini. Namun pita adsorpsi pada bilangan gelombang disekitar $1492 \mathrm{~cm}^{-1}$ juga muncul pada sampel yang menunjukkan sisi asam Brønsted dan Lewis.

\section{Uji Aktivitas Katalitik}

\section{A. Penentuan Sudut Putar Bidang Polarisasi Spesifik Glukosa}

Penentuan sudut putar bidang polarisasi spesifik glukosa $\left(\alpha_{\mathrm{sg}}\right)$ diperoleh dengan cara mengukur sudut putar bidang polarisasi pada rentang konsentrasi glukosa yang berbeda menggunakan polarimeter. Kemudian mengalurkannya pada sumbu X$\mathrm{Y}$, dimana sumbu $\mathrm{X}$ adalah konsentrasi glukosa dan sumbu $\mathrm{Y}$ adalah sudut putar bidang polarisasi $\left(\alpha_{o b s}\right)$. Grafik kalibrasi glukosa dapat dilihat pada Gambar 3.

Dari grafik Gambar 3 dapat dilakukan linearisasi, sehingga diperoleh 
sudut putar bidang polarisasi glukosa $\left(\alpha_{\text {obs }}\right)$ sebesar $+225,71$.

Tabel 2 Jumlah sisi asam Brønsted dan Lewis

\begin{tabular}{cccc}
\hline Sampel & $\begin{array}{r}\text { Brønsted } \\
(\mathrm{mmol} / \mathrm{g})\end{array}$ & $\begin{array}{r}\text { Lewis } \\
(\mathrm{mmol} / \mathrm{g})\end{array}$ & $\begin{array}{r}\text { Luas puncak } \\
\text { pada } 1492 \\
\mathrm{~cm}^{-1}\end{array}$ \\
\hline Zeolit & 0,153 & - & 5,462 \\
Modifika & & & \\
si Ti 0,2 & & & \\
M & & & \\
\hline
\end{tabular}

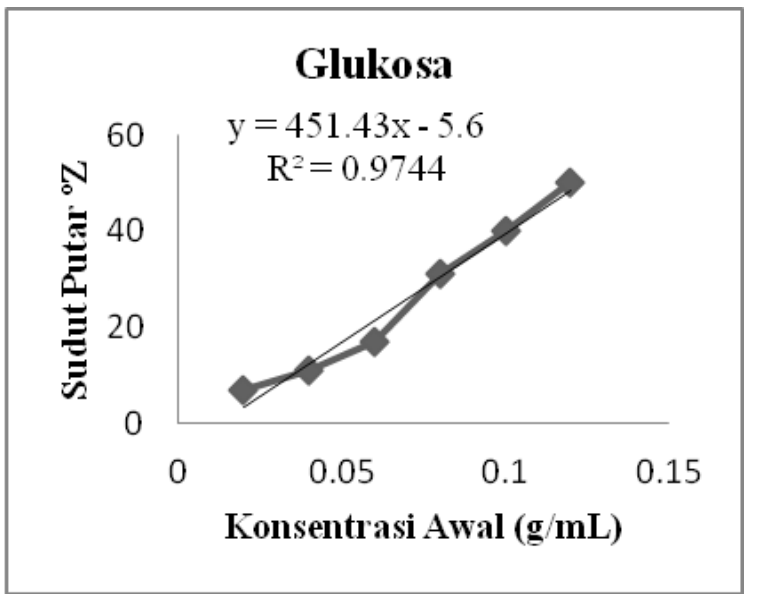

Gambar 3 Grafik kalibrasi glukosa

\section{B. Penentuan Sudut Putar Bidang Polarisasi Spesifik Fruktosa}

Penentuan sudut putar bidang polarisasi spesifik fruktosa $\left(\alpha_{\mathrm{sf}}\right)$ diperoleh dengan cara mengukur sudut putar bidang polarisasi pada rentang konsentrasi fruktosa yang berbeda menggunakan polarimeter. Kemudian mengalurkannya pada sumbu X$\mathrm{Y}$, dimana sumbu $\mathrm{X}$ adalah konsentrasi fruktosa dan sumbu $\mathrm{Y}$ adalah sudut putar bidang polarisasi $\left(\alpha_{o b s}\right)$. Grafik kalibrasi fruktosa dapat dilihat pada Gambar 4.

Dari grafik Gambar 4 dapat dilakukan linearisasi, sehingga diperoleh sudut putar bidang polarisasi fruktosa $\left(\alpha_{\text {obs }}\right)$ sebesar $-252,85$.

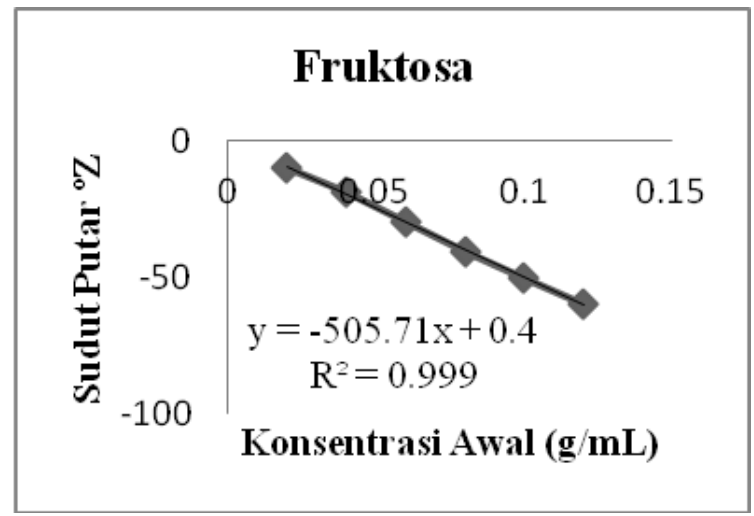

Gambar 4 Grafik kalibrasi fruktosa

\section{Isomerisasi Glukosa}

Isomerisasi glukosa dilakukan untuk mengetahui banyaknya konversi glukosa yang dihasilkan dari reaksi. Isomerisasi dilakukan menggunakan katalis zeolit alam, $\mathrm{H}$-zeolit dan Ti-H-zeolit sehingga diperoleh perbandingan konversi glukosa yang dihasilkan dari ketiganya dengan variasi waktu masing-masing untuk mengetahui waktu terbaik yang digunakan dalam reaksi isomerisasi glukosa, artinya konsentrasi glukosa awal akan berkurang setelah terjadinya reaksi karena diasumsikan bahwa glukosa telah membentuk isomernya. Konsentrasi glukosa yang terbentuk setelah reaksi diketahui dengan mengukur sudut putar bidang polarisasinya menggunakan polarimeter. Adapun konsentrasi glukosa hasil isomerisasi setiap waktu dapat dilihat pada Tabel 3.

Tabel 3 Konsentrasi hasil isomerisasi glukosa setiap waktu

\begin{tabular}{ccccc}
\hline Sampel & \multicolumn{4}{c}{ Konsentrasi Glukosa (g/mL) } \\
\cline { 2 - 5 } & $\begin{array}{c}30 \\
\text { menit }\end{array}$ & $\begin{array}{c}60 \\
\text { menit }\end{array}$ & $\begin{array}{c}90 \\
\text { menit }\end{array}$ & $\begin{array}{c}120 \\
\text { menit }\end{array}$ \\
\hline $\begin{array}{c}\text { Zeolit } \\
\text { Alam }\end{array}$ & 0,0920 & 0,0841 & 0,0815 & 0,0789 \\
H- & & 0,0815 & 0,0789 & 0,0815 \\
$\begin{array}{c}\text { Zeolit } \\
\text { Alam }\end{array}$ & 0,0841 & & & \\
Ti-H- \\
$\begin{array}{c}\text { Zeolit } \\
\text { Alam }\end{array}$ & 0,0815 & 0,0815 & 0,0789 & 0,0737 \\
\hline
\end{tabular}


Tabel 3 menjelaskan bahwa katalis zeolit alam, H-zeolit alam dan Ti-H-zeolit alam pada reaksi isomerisasi glukosa selama 30, 60, 90 dan 120 menit cenderung mengalami penurunan konsentrasi glukosa. Hal tersebut menyatakan bahwa semakin kecil konsentrasi glukosa hasil isomerisasi, semakin besar \% konversi glukosa atau semakin banyak glukosa yang telah terisomerisasi. Konsentrasi hasil iomerisasi glukosa merupakan konsentrasi glukosa sisa isomerisasi. Pengurangan glukosa awal terhadap glukosa sisa isomerisasi merupakan glukosa yang telah terisomerisasi, dimungkinkan seperti fruktosa, manosa ataupun produk samping yang lain. Adapun grafik hubungan antara $\%$ konversi glukosa terhadap waktu isomerisasi dapat dilihat pada Gambar 5.

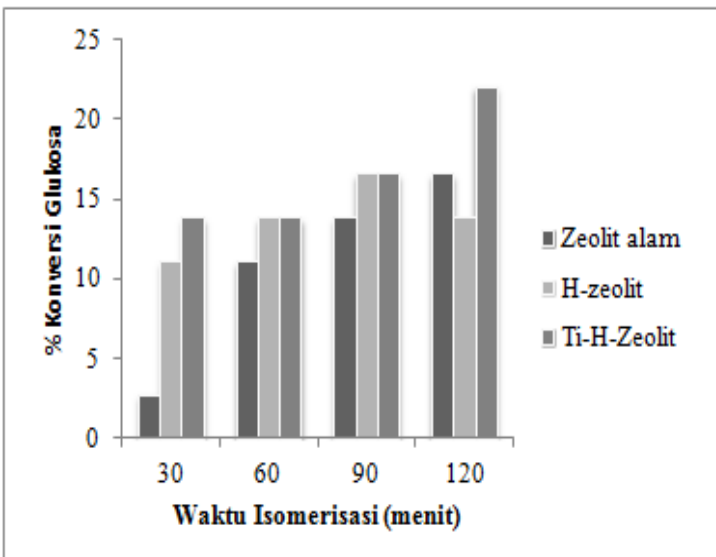

Gambar 5 Grafik hubungan antara \% konversi glukosa terhadap waktu isomerisasi

Konversi dinyatakan dalam persen (\%) dan hasil konversi glukosa dapat dilihat pada Gambar 5 yang menyatakan bahwa \% konversi glukosa terbesar dihasilkan oleh reaksi isomerisasi glukosa pada suhu 110 ${ }^{\circ} \mathrm{C}$ menggunakan katalis zeolit alam selama 120 menit sebesar $16,59 \%$, menggunakan katalis H-zeolit alam selama 90 menit sebesar $16,59 \%$ dan menggunakan katalis Ti-H-zeolit selama 120 menit sebesar 22,09 $\%$. Hal ini disebabkan oleh pengaruh keasaman yang menunjukkan bahwa zeolit alam memiliki keasaman yang lebih kecil dibandingkan dengan $\mathrm{H}$-zeolit dan Ti-H- zeolit memiliki keasaman yang lebih besar jika dibandingkan dengan $\mathrm{H}$-zeolit (zeolit alam < H-zeolit alam < Ti-H-zeolit alam). Oleh karena itu dapat diketahui bahwa \% konversi glukosa sebanding dengan nilai keasaman katalis. Semakin besar keasaman katalis semakin besar pula \% konversi glukosa. Sehingga, dapat disimpulkan aktivitas terbaik reaksi isomerisasi glukosa dilakukan menggunakan katalis Ti-H-zeolit alam.

Moliner, dkk (2010) menjelaskan bahwa reaksi isomerisasi glukosa menjadi fruktosa mengunakan Sn-Beta melalui jalur pergeseran hidrida. Studi kinetika reaksi isomerisasi melaporkan bahwa asam dan logam tertentu dapat mentransfer hidrogen langsung melalui pergeseran hidrida antara C-2 dan C-1. Hal tersebut dapat dianalogikan terhadap logam $\mathrm{Ti}$ dalam zeolit alam jenis mordenit. Sehingga mekanisme reaksi isomerisasi glukosa menggunakan zeolit alam yang telah dimodifikasi logam $\mathrm{Ti}$ mengikuti mekanisme pergeseran hidrida seperti Gambar 6.
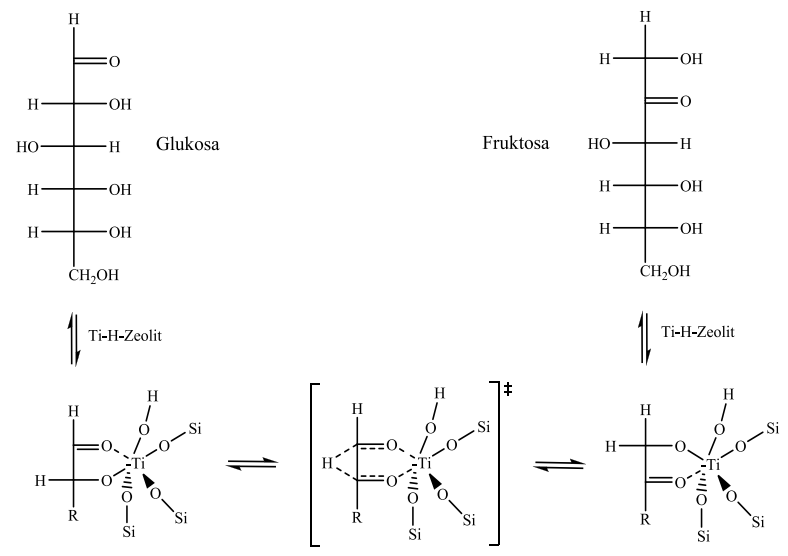

Gambar 6 Dugaan reaksi isomerisasi glukosa dengan katalis zeolit modifikasi logam $\mathrm{Ti}$

Hasil isomerisasi glukosa yang berupa konsentrasi glukosa sisa isomerisasi digunakan untuk analisa kinetika reaksi isomerisasi glukosa menggunakan katalis zeolit alam, H-zeolit alam dan Ti-H-zeolit alam Malang. Orde reaksi ketiga jenis 
katalis dapat ditentukan; apakah orde-0, orde-1, atau orde-2. Sehingga, dihasilkan grafik linear antara konsentrasi glukosa sisa isomerisasi setiap waktu (St) dan waktu $\mathrm{t}$ (detik). Dugaan orde reaksi dapat dilihat pada Tabel 4.

Tabel 4 menunjukkan bahwa nilai regresi isomerisasi glukosa, orde-2 memberikan hubungan yang lebih linear dibandingkan dengan orde lainnya. Karena itu dapat disimpulkan bahwa reaksi isomerisasi glukosa merupakan reaksi orde dua.

Tabel 4 Regresi penentuan orde reaksi isomerisasi glukosa menggunakan zeolit alam, H-zeolit alam dan TiH-zeolit alam

\begin{tabular}{cccc}
\hline & Regresi & & $\begin{array}{c}\text { Orde } \\
\text { Reaksi }\end{array}$ \\
\cline { 1 - 3 } Ti-H- & H-Zeolit & Zeolit & \\
Alam & Alam & Alam & \\
\hline 0,8292 & 0,6538 & 0,9542 & 0 \\
0,8469 & 0,658 & 0,9579 & 1 \\
0,8635 & 0,6644 & 0,9628 & 2 \\
\hline
\end{tabular}

\section{KESIMPULAN}

Dari hasil penelitian yang telah dilakukan dapat disimpulkan bahwa sebagai berikut:

1. Keasaman adsorpsi amoniak katalis zeolit alam, H-zeolit dan Ti-H-zeolit alam Malang berturut-turut adalah sebesar 0,188; 0,281 dan 0,387 mmol/g. Keasaman adsorpsi piridin katalis Ti-Hzeolit alam Malang memiliki sisi asam Brønsted sebesar 0,153 mmol/g.

2. Aktivitas katalis zeolit alam diperoleh pada reaksi isomerisasi glukosa selama 120 menit dengan \% konversi glukosa sebesar 16,59\%, katalis H-zeolit alam selama 90 menit dengan \% konversi glukosa sebesar $16,59 \%$ serta katalis TiH-zeolit alam Malang selama 120 menit dengan \% konversi glukosa sebesar $22,09 \%$.

\section{DAFTAR PUSTAKA}

Al-Qurthubi, I. 2009. Tafsir Al-Qurthubi. Jakarta: Pustaka Azzam.

Augustine, R.L. 1996. Heterogeneous Catalysis for the Synthetic Chemist. New York: Marcel Dekker Inc.

Botianovi, A. 2012. Modifikasi Zeolit Alam Malang dari mikropori ke Mesopori dengan Penambahan Surfaktan $\mathrm{CTaBr}$

(Cetyltrimethylammoniumbromide).

Skripsi. Malang: Jurusan Kimia Fakultas Sains dan Teknologi Universitas Islam Negeri Maulana Malik Ibrahim Malang.

Emeis C. A. 1993. Determination of Integrated Molar Extinction Coefficients for Infrared Absorption of Pyridine Adsorbed on Solid Acid Catalysts. Journal of Catalysis, 141 : 347-354.

Gaily, M. H., Elhasan, B.M., Abasaeed, E. 2010. Isomerization and Kinetics of Glucose into Fructose. International Journal of Engineering \& Technology IJET-IJENS, Vol: 10 No: 03.

Hagedus, L.L. 1987. Catalysts Design Progress and Perspectives. New York: John Wiley and Sons.

Moliner, M., Leshkov, Y., and Davis, M. E. 2010. Tin-Containing Zeolites Are Highly Active Catalysts For The Isomerization of Glucose In Water. PNAS Early Edition, 1-5.

Platon, A. and Thomson. W. J. 2003. Quantitative Lewis/ Brønsted Ratios using DRIFTS. Applied Catalysis Industrial Engineering Chemistry Research, 42: 5988-5992.

Shihab, M. Q. 2003. Tafsir Al-Misbah: Pesan, Kesan dan Keserasian AlQur'an. Jakarta: Lentera Hati.

Situmeang, R., dan Fransisca, N. 2011. Study of $\mathrm{Co}_{3} \mathrm{O}_{4} / \mathrm{NiFe}_{2} \mathrm{O}_{4}$ Catalyst for Glucose Conversion in the Low Temperature. Prosiding Seminar Nasional Sains dan Teknologi - IV, ISBN 978-979-8510-34-2. 
ALCHEMY, Vol. 3 No. 1 April 2014, hal 31-38

Zhang, Y., Hidajat, K., dan A.K. Ray. 2004. Optimal Design and Operation of SMB Bioreactor: Production of High Fructose Syrup by
Isomerization of Glucose.

Biochemical Engineering Journal, Vol: 21 No: 111-121. 